\title{
Kepatuhan Perawat Dalam Implementasi Surgical Safety Checklist Terhadap Insiden Keselamatan Pasien Ponek di Rumah Sakit Semarang
}

\author{
Susi Nurhayati, Suwandi \\ STIKES Karya Husada Semarang, Jl. Kompol R. Soekanto No. 46 Semarang \\ Email: susinurhayati74@yahoo.com
}

\begin{abstract}
Abstrak
Latar Belakang : Keselamatan pasien (patient safety) merupakan proses dalam suatu rumah sakit yang memberikan pelayanan pasien yang lebih aman. Surgery safety ceklist WHO diterjemahkan dalam bentuk formulir yang diisi dengan melakukan ceklist. Tujuan: untuk mengetahui hubungan kepatuhan perawat kamar bedah dalam implementasi surgical safety checklist terhadap insiden keselamatan pasien ponek di ruang bedah sentral RSUD Tugurejo Semarang. Metode : Penelitian kuantitatif ini menggunakan 30 responden. Instrumen yang digunakan adalah Surgery safety ceklist who yang diadaptasi oleh RSUD Tugurejo. Pengambilan sampel dengan observasi. Hasil : Implementasi Surgical Safety Checklist sebanyak 28 responden patuh (93,3\% ), dan sebagian kecil tidak patuh sebanyak 2 responden ( 6,7\% ). Uji statistik dengan Pearson Chi Square didapatkan bahwa kepatuhan perawat kamar bedah dalam Implementasi Surgical Safety Checklist terhadap insiden keselamatan pasien ponek di ruang bedah sentral RSUD Tugurejo Semarang $(p=0.131>\alpha=0,05)$ Kesimpulan: Tidak ada hubungan yang bermakna antara kepatuhan perawat kamar bedah dalam implemetasi Surgical Safety Checklist terhadap insiden keselamatan pasien ponek dengan p value 0,131.
\end{abstract}

Kata kunci : surgical safety checklist; pasient safety; insiden keselamatan pasien ponek.

\section{Abstract}

Background: Patient safety is a process in a hospital that provides safer patient services. WHO Surgery safety checklist is translated in the form of a form filled in by conducting a checklist. Purpose: The aim was to determine the relationship of compliance with the operating room nurses in the implementation of the surgical safety checklist against the incidence of safety of patients with ponek in the central surgery room of the Tugurejo Hospital Semarang. Method: This quantitative research uses 30 respondents. The instrument used is the Surgery safety checklist who has been adapted by Tugurejo General Hospital. Sampling method with observation. Results: The Implementasi of Surgical Safety Checklist 28 respondents obeyed (93,3\%) and a small portion is not obedient $(6,7 \%)$. The statistical test with Pearson Chi Square showed that relationship between the compliance of the operating room nurses in the Surgical Safety Checklist against the incidence of safety of ponek patients $(p=0.131>a=0,05)$. Conclusion: Showed that there was no significant relationship between the compliance of the operating room nurses in the Surgical Safety Checklist against the incidence of safety of ponek patients.

Keywords: Surgical Safety Checklist, patient safety; incident of ponek patient safety. 


\section{LATAR BELAKANG}

Keselamatan (safety) telah menjadi isu global termasuk juga untuk rumah sakit (DEPKES RI, 2015). Program Keselamatan Pasien safe surgery saves lifes sebagai bagian dari upaya WHO untuk mengurangi jumlah kematian bedah di seluruh dunia(World Health Organization, 2008). Tujuan dari program ini adalah untuk memanfaatkan komitmen dan kemauan klinis untuk mengatasi isu-isu keselamatan yang penting, termasuk praktek-praktek keselamatan anestesi yang tidak memadai, mencegah infeksi bedah dan komunikasi yang buruk di antara anggota tim. Untuk membantu tim bedah dalam mengurangi jumlah kejadian ini, WHO menghasilkan rancangan berupa checklist keselamatan pasien di kamar bedah sebagai media informasi yang dapat membina komunikasi yang lebih baik dan kerjasama antara disiplin klinis.

Rentang tahun 2000 dan 2015, rasio kematian maternal global menurun sebesar 37 persen, dan angka kematian di bawah 5 tahun turun sebesar 44 persen. Namun, 303.000 wanita meninggal dunia selama kehamilan atau persalinan dan 5,9 juta anak di bawah usia 5 tahun meninggal dunia di seluruh dunia pada tahun 2015. Sebagian besar kematian ini disebabkan oleh penyebab yang dapat dicegah (UN, 2017).

Pemerintah mengurangi resiko kematian ibu maternal dan neonatal melalui Kementrian Kesehatan,dengan membuat sistem yang terpadu pada tingkat nasional dan regional. Pelayanan obstetri dan neonatal regional merupakan upaya penyediaan pelayanan bagi ibu dan bayi baru lahir secara terpadu dalam bentuk Pelayanan Obstetri Neonatal Emergensi Komprehensif (PONEK) di rumah sakit dan Pelayanan Obstetri Neonatal Emergensi Dasar (PONED) di tingkat puskesmas(Kemenkes R.I, 2012).

Di Jawa tengah jumlah kasus kematian ibu tahun 2015 yang sebanyak 619 kasus, ditahun 2016 mengalami penurunan sebanyak 17 kasus, total kasus tahun 2016, 602 kasus. Dengan demikian angka kematian ibu ( AKI) Provinsi Jawa Tengah juga mengalami penurunan dari 111,16 per 100.000 kelahiran hidup pada tahun 2015 menjadi 109,65 per 100.000 kelahiran hidup pada tahun 2016 (Dinas Kesehatan Provinsi Jawa Tengah, 2016).
RSUD Tugurejo Semarang memiliki SPO (Standar Prosedur Operasional) keselamatan pasien, RS ini telah berkomitmen pada keselamatan pasien/patien safety. Data tindakan operasi elektif sectio caesaria (SC) periode Januari - Desember 2016 sejumlah 700 kasus sedangkan untuk kasus sc cito sebanyak 522 kasus SC atau $74,5 \%$ per tahun sedangkan untuk periode Januari - Juli 2017 sejumlah 384 kasus SC. Tingginya kasus operasi SC yaitu $74,5 \%$ pada tahun 2016, memerlukan peran sentral dan strategis dari perawat kamar bedah dalam melakukan pelayanan operasi SC yang komprehensif secara team work yang berorientasi pada keselamatan pasien/ patient safety.

Keterbatasan jumlah kamar operasi (3 kamar operasi ) dibandingkan jumlah kasus pembedahan terutama kasus obstetri dan genekologi yang mencapai 837 kasus tahun 2017, serta tenaga perawat 33 orang dengan latar belakang pendidikan D3 keperawatan 12 orang dan S1 keperawatan dan Ners 20, S2 keperawatan 1 orang, lama bekerja, menyebabkan beberapa masalah sering muncul.

Peneliti ingin mengetahui apakah faktor-faktor diatas berpengaruh terhadap Kepatuhan Perawat Kamar Bedah dalam Implementasi Surgical Safety Cecklist dalam Pelayanan PONEK di kamar bedah. Tujuan penelitian ini untuk mengetahui hubungan kepatuhan perawat kamar bedah dalam implementasi surgical safety checklist terhadap insiden keselamatan pasien ponek di ruang bedah sentral RSUD Tugurejo Semarang.

\section{METODE}

Penelitian ini adalah penelitian kuantitatif yaitu dengan memperoleh data yang berbentuk angka atau data kualitatif yang disajikan dalam angka (Priyono, 2016). Pendekatan secara deskriptif yaitu penelitian yang dilakukan untuk memberikan gambaran yang lebih detail mengenai suatu gejala atau fenomena(Priyono, 2016).

Desain penelitian ini adalah deskriptif analitik yaitu penelitian yang mencoba menggali mengapa fenomena kesehatan itu terjadi. Kemudian melakukan analisis dinamika korelasi antara fenomena atau faktor resiko dengan faktor efek. Yang dimaksud dengan faktor efek adalah 
suatu akibat dari adanya faktor resiko. Faktor resiko adalah suatu fenomena yang mengakibatkan terjadinya efek (Notoadmodjo, 2010). Rancangan penelitian secara cross sectional, penelitian yang dilakukan dalam satu waktu tertentu. Penelitian ini hanya digunakan dalam waktu yang tertentu, dan tidak akan dilakukan penelitian lain di waktu yang berbeda untuk diperbandingkan(Priyono, 2016).

Penelitian dilakukan pada bulan 16 Desember 2018 - 15 Januari 2019 di kamar bedah RSUD Tugurejo Semarang. Instrumen dalam penelitian ini yang berupa lembar observasi yang diambil dari SPO format ceck list kamar bedah (surgical checlist). Metode observasi yang dilakukan dengan melengkapi format/ blangko pengamatan sebagai instrumen. Format yang disusun berisi item-item tentang kejadian atau tingkah laku yang digambarkan akan terjadi.

HASIL

\section{Karakteristik responden Umur}

Tabel 1 Karakteristik Responden berdasarkan Umur

\begin{tabular}{lcc}
\hline \multicolumn{1}{c}{ Karakteristik } & $\mathrm{n}$ & $\%$ \\
\hline Umur & & \\
Dewasa awal (26 - 35 tahun) & 13 & 43,3 \\
Dewasa akhir (36 - 45 tahun) & 16 & 53,4 \\
Lansia akhir (56 - 65 tahun) & 1 & 3,3 \\
Total & 30 & 100
\end{tabular}

Dari tabel 1. terlihat bahwa 30 responden yang masuk dalam penelitian ini terbanyak pada kelompok umur dewasa akhir (36 - 45 tahun) dengan prosentasi $53,4 \%$, selanjutnya pada kelompok umur dewasa awal (26 - 35 tahun) dengan prosentasi $43,3 \%$ dan lansia akhir (56 65 tahun) 3,3\%(Depkes, n.d.).

Tabel 2 Lama kerja di kamar Bedah RSUD Tugurejo Semarang

\begin{tabular}{lcc}
\hline \multicolumn{1}{c}{ Karakteristik } & $\mathrm{n}$ & $\%$ \\
\hline Lama Bekerja & & \\
$2-4$ tahun & 9 & 30 \\
$5-9$ tahun & 11 & 36,7 \\
$\geq 10$ tahun & 10 & 33,3 \\
Total & 30 & 100 \\
\hline
\end{tabular}

Berdasar tabel 2, lama kerja terbanyak pada 5 - 9 tahun dengan jumlah $36,7 \%$, diikuti lama kerja > 10 tahun $33,3 \%$ dan lama kerja $2-4$ tahun $30 \%$.

Jenis kelamin

Tabel 3. Jenis Kelamin

\begin{tabular}{lcc}
\hline Karakteristik & $\mathrm{n}$ & $\%$ \\
\hline Laki-laki & 24 & 80 \\
Perempuan & 6 & 20 \\
Total & 30 & 100 \\
\hline
\end{tabular}

Dari tabel 3 jenis kelamin laki - laki lebih mendominasi dengan jumlah $80 \%$ dari jenis kelamin perempuan $20 \%$.

Status Kepegawaian

Tabel 4. Status Kepegawaian

\begin{tabular}{llc}
\hline Karakteristik & $\mathrm{n}$ & $\%$ \\
\hline PNS & 17 & 56,7 \\
BLUD & 13 & 43,3 \\
Total & 30 & 100 \\
\hline
\end{tabular}

Dari tabel 4 terlihat bahwa 30 responden yang masuk dalam penelitian ini terbanyak status kepegawaian PNS ( 56,7\% ).

Pendidikan

Tabel 5. Pendidikan

\begin{tabular}{lcc}
\hline \multicolumn{1}{c}{ Karakteristik } & $\mathrm{n}$ & $\%$ \\
\hline DIII & 12 & 40 \\
S1 Keperawatan + Ners & 17 & 56,7 \\
S2 & 1 & 3,3 \\
Total & 30 & 100 \\
\hline
\end{tabular}

Berdasar tabel 5, dari 30 Responden, terbanyak dengan pendidikan S1 keperawatan + Ners dengan $56,7 \%$, diikuti DIII dengan $40 \%$.

Kepatuhan perawat kamar bedah dalam implementasi Surgical Safety Checklist

Tabel 6 Kepatuhan perawat kamar bedah dalam implementasi Surgical Safety Checklist

\begin{tabular}{lcc}
\hline \multicolumn{1}{c}{ Kepatuhan } & $\mathrm{n}$ & $\%$ \\
\hline Patuh & 28 & 93,3 \\
Tidak Patuh & 2 & 6,7 \\
Total & 30 & 100 \\
\hline
\end{tabular}


Nurhayati, Kepatuhan Perawat Dalam Implementasi Surgical Safety Checklist Terhadap Insiden Keselamatan Pasien.... SJKP, Vol. 6, No. 1, Juni 2019,

Berdasarkan tabel 6 Hasil observasi kepatuhan perawat kamar bedah dalam implementasi Surgical Safety Checklist dari 30 responden terhadap 30 tindakan pasien yang menjalani seksio sesarea terdapat 2 pasien $(6,7 \%)$ yang dikategorikan tidak patuh karena ada item yang tidak dilakukan, sedang 28 pasien $(93,3 \%)$ lainnya bisa dilakukan sepenuhnya tanpa ada item yang terlewatkan. Sedangkan pada table 7 menunjukkan tidak ada insiden sejumlah $93,3 \%$. Insiden Keselamatan Pasien PONEK ( Pelayanan Obstetri Neonatus Emergency Komprehensif

Tabel 7 Insidenkeselamatan pasien PONEK

\begin{tabular}{lcc}
\hline \multicolumn{1}{c}{ Insiden pada pasien Ponek } & $\mathrm{n}$ & $\%$ \\
\hline Insiden & 2 & 6,7 \\
Tidak Insiden & 28 & 93,3 \\
Total & 30 & 100 \\
\hline
\end{tabular}

Hal tersebut menunjukkan bahwa insiden keselamatan pasien ponek baik.

Hubungan kepatuhan perawat kamar bedah dengan insiden keselamatan pada pasien Ponek

Tabel 8. Analisa hubungan kepatuhan perawat kamar bedah dalam implementasi surgical safety checklist

\begin{tabular}{cccccccc}
\hline \multirow{2}{*}{ Kepatuhan SSCL } & \multicolumn{2}{c}{ Ada insiden } & \multicolumn{2}{c}{ Tidak ada insiden } & \multicolumn{2}{c}{ Jumlah } & P Value \\
\cline { 2 - 9 } & $\mathrm{n}$ & $\%$ & $\mathrm{n}$ & $\%$ & $\mathrm{n}$ & $\%$ & \\
\hline Patuh & 1 & 3,3 & 27 & 90 & 28 & 93,3 & 0,131 \\
Tidak patuh & 1 & 3,3 & 1 & 3.3 & 2 & 6,7 & \\
\hline Total & 2 & 6.7 & 28 & 93,3 & 30 & 100 & \\
\hline
\end{tabular}

Dari hasil uji Pearson Chi Square didapatkan $p=0,131>0,05(\propto<0,005)$, Hasil ini menunjukkan bahwa tidak terdapat hubungan bermakna antara kepatuhan perawat kamar bedah dalam implemetasi Surgical Safety Checklist terhadap insiden keselamatan pasien ponek.

\section{PEMBAHASAN}

Berdasarkan hasil penelitian disebutkan perawat kamar bedah RSUD Tugurejo Semarang sebagian besar patuh dalam implementasi surgical safety shecklist sebanyak 28 responden ( $93,3 \%$ ), dan sebagian kecil tidak patuh sebanyak 2 responden $(6,7 \%)$. Implementasi surgical safety checklist ini dibagi dalam tiga fase ( sign in, time out, sign out ), yang merupakan tanggung jawab tim bedah ( dokter, perawat, ahli anestesi ) untuk mengisi setiap bagian dari surgical safety checklist. Surgical safety sistem yang menggunakan checklist untuk memantau keselamatan pasien merupakan suatu alat atau sarana yang sangat penting dalam penerapan patient safety atau keselamatan pasien khususnya di dalam ruang operasi.

Kepatuhan perawat mengimplementasikan surgical check list dipengaruhi dengan adanya kebijakan dan adanya standar operasional prosedur yang bada di rumah sakit (Sandrawati, 2013). Selain itu budaya keselamatan pasien juga dilihat dari sikap dan persepsi petugas di kamar bedah dalam memberikan pelayanan yang aman untuk pasien dan petugas (Sandrawati, 2013).

Fase sign In dilakukan sebelum induksi anestesi dilakukan, koordinator akan memeriksa secara verbal terkait identitas pasien apakah telah dikonfirmasi, prosedur dan sisi operasi sudah benar, sisi yang akan dioperasi telah ditandai, persetujuan untuk operasi telah diberikan, pulse oksimeter pada pasien berfungsi, serta resiko kehilangan darah. Fase time out dilakukan stelah pasien dilakukan tindakan anestesi oleh ahli anestesi dan sebelum dilakukan tindakan pembedahan. Seluruh anggota tim menyebutkan secara verbal nama dan perannya masing-masing ( operator, asisten, 
instrumen sirkuler, ahli anestesi ), mengecek kembali kebenaran indentitas pasien, prosedur pembedahan serta lokasi pembedahan, antibiotik profilaksis, hal kritis atau langkah yang tak terduga akan diambil, estimasi lama operasi, antisipasi kehilangan darah, tim anestesi terdapat hal penting mengenai keadaan pasien yang perlu diperhatikan, sudah sterilkah alat, dan apakah ada hal khusus mengenai peralatan. Fase time out tim bedah kembali mengkonfirmasi dihadapan tim sebelum penutupan area operasi dengan menyebutkan kembali : nama prosedur tindakan, kelengkapan hitung instrumen ( apakah sudah sesuai ), gaas/kasa, jarum sudah sesuai, label spesimen sudah diberikan, dan kepada operator dokter anestesi dan tim keperawatan, mengkonfirmasi apakah ada pesan khusus dalam pemulihan pasien. Sandrawati (2017) menyebutkan pelaksanaan time out tidak efektif dilakukan $(0,323)$

Berdasarkan hasil penelitian dapat diketahui bahwa insiden keselamatan pada pasien ponek sebesar $6,7 \%$, tidak ada insiden keselamatan pada pasien ponek sebesar $93,3 \%$. Insiden yang ditemui berupa 1 kasus sentinel dan 1 kasus infeksi luka operasi ( surgical site infeksion ). Infeksi luka operasi ( ILO ) adalah infeksi yang terjadi pada tempat insisi dalam 30 hari paska operasi atau dalam kurun 1 tahun apabila terdapat implant (Alsen \& Sihombing, 2014). Dikatakan terjadi infeksi luka operasi apabila dijumpai satu diantara kriteria: adanya drainage purulen dari insisi superfisial, organisme yang diisolasi dari kultur jaringan atau cairan dari insisi superfisialis yang diambil secara asepsis, setidaknya dijumpai satu dari tanda dan gejala infeksi ( nyeri, edema lokal, eritema, rabaan hangat dan insisi superfisialis dibuka dengan sengaja oleh ahli bedah, kecuali kulturnya negatif.

Hasil analisa data dapat disimpulkan bahwa tidak ada hubungan yang bermakna antara kepatuhan perawat kamar bedah dalam implementasi surgical safety checklist dan insiden keselamatan pasien Ponek. Penelitian lain juga menyebutkan bahwa tidak ada hubungan yang bermakna antara pelaksanaan surgical safety checklist dan kejadian infeksi post operasi mayor (Widiyaningsih, Eni Kusyati, n.d.). Disebutkan, dari hasil olah data dengan Chi Square, maka didapatkan nilai continuity correction sebesar
1.660 dengan $p$ value $0,198<0,05$ maka dapat disimpulkan tidak ada hubungan yang bermakna antara pelaksanaan surgical safety checklist dan kejadian infeksi post operasi mayor

Hal senada juga disebutkan bahwa tidak terdapat hubungan bermakna antara kepatuhan penerapan surgical safety checklist dengan tidak terjadinya infeksi pasca seksio sesarea (Emilia, Prawitasari, \& Prawirodihardjo, 2018). Hasil olah data dengan person chi square, diperoleh hasil 0,078 dengan $p$ value $>0,05$. Disebutkan bahwa terdapat hubungan yang bermakna antara kepatuhan penerapan surgical safety checklist dengan lamanya hari rawat inap di rumah sakit pada pasien seksio sesarea. Hasil olah data dengan person chi square, diperoleh hasil 0,006 dengan $p$ value $<0,05$. Disini juga disebutkan bahwa terdapat hubungan yang bermakna antara kepatuhan penerapan Surgical Safety Checklist dengan lamanya hari rawat inap di rumah sakit pada pasien seksio sesarea. Hasil olah data dengan person chi square, diperoleh hasil 0,006 dengan $p$ value $<0,05$.

\section{KESIMPULAN DAN SARAN}

Terdapat $93,3 \%$ perawat yang patuh dalam implementasi surgical safety checklist dan perawat tidak patuh sebanyak $6,7 \%$. Adanya data insiden keselamatan pada pasien ponek sejumlah $6,7 \%$. Analisa chi square menyebutkan tidak ada hubungan antara kepatuhan perawat kamar bedah dalam implementasi surgical safety checklist terhadap insiden keselamatan pasien Ponek dengan $p$ value $=0,131(\propto<0,05)$.

RSUD Tugurejo Semarang dalam penerapan prosedur surgical safety checklist di kamar bedah dapat mencegah dan mengurangi cedera pasien yang berasal dari proses pelayanan kesehatan sehingga diharapkan prosedur surgical safety checklist ini dapat diterapkan sepenuhnya. Peningkatan upaya monitoring pasien pasca operasi terutama pasien pasca sectio caesaria terkait dengan kejadian surgical site infektion ILO / IDO, berkoordinasi teknis dengan IPCLN (Infektions Prevention Contol Link Nurse ) dan IPCN ( Infektions Prevention Contol Nurse ). Tim kamar bedah, sebagai bahan masukan perlunya pelaksanaan sosialisasi penerapan surgical safety checklist secara berkala dan berkelanjutan untuk 
memastikan terselenggaranya keselamatan pasien kamar bedah secara maksimal.

\section{REFFERENSI}

Alsen, M., \& Sihombing, R. (2014). Infeksi Luka Operasi, (3), 229-235.

Depkes. (n.d.). KATEGORI UMUR MENURUT DEPKES ( 2009 ). Retrieved from https://yhantiaritra.wordpress.com/2015/06/0 3/kategori-umur-menurut-depkes/

DEPKES RI. (2015). Pedoman Nasional Keselamatan Pasien Rumah Sakit (III). Jakarta. Retrieved from https://kupdf.com/queue/pedoman-nasionalkeselamatan-pasien-rumahsakit_58d33835dc0d604f7ac346aa_pdf?que ue_id $=-$

$1 \& \mathrm{x}=1519313246 \& z=M T g w L j \mid 1$ NC4yNDluM TMx

Dinas Kesehatan Provinsi Jawa Tengah. (2016). Profil Kesehatan Provinsi Jawa Tengah, 3511351(24).

Dra. Atin Karjatin, M. K. (2016). Keperawatan Maternitas (cetakan pe). Jakarta: Kementerian Kesehatan.

Emilia, O., Prawitasari, S., \& Prawirodihardjo, L. (2018). Hubungan Kepatuhan Tim Bedah dalam Penerapan Surgery Safety Checklist ( Ssc ) Dengan Infeksi Luka Operasi dan Lama Rawat Inap Pada Pasien Seksio Sesarea di Rumah Sakit Umum Daerah Kabupaten Barru, 5(3), 145-158. https://doi.org/10.22146/jkr.39666

Franata Lucky. (2017). Penerapan five steps to safer surgery dalam meningkatkan kepatuhan pengisian checklist di RSKB Annur Yogyakarta. Program Studi Manajemen Rumah Sakit Universitas Muhammadiyah Yogyakarta

Kemenkes R.I. (2012). Pedoman Penyelenggara PONEK 24 jam di Rumah sakit, (November 2012), 1 of 71.
Kusumaningtyas, S., Kristiyawati, S. P., \& Purnomo, S. E. C. (2013). Faktor - Faktor Yang Berhubungan Dengan Tingkat Kepatuhan Perawat Melakukan Cuci Tangan Di Rs.Telogoejo Semarang. Jurnal IImu Keperawatan Dan Kebidanan STIKES Telogorejo Semarang, 1(4), 1-10.

Notoadmodjo, S. (2010). Metodologi Menelitian Kesehatan (ed. Rev). Jakarta: Rineka Cipta.

Pasien, K. K., \& Sakit, R. (2015). Pedoman Pelaporan Insiden Keselamatan Pasien (Ikp) (Patient Safety Incident Report). Retrieved from http://www.pdpersi.co.id/kanalpersi/website_ ikprs/content/pedoman_pelaporan.pdf

Priyono. (2016). Metode Penelitian Kuantitatif.

Sandrawati Juliana, Stefanus Supriyanto, Thini Nurul. (2013). Rekomendasi untuk meningkatkan kepatuhan penerapan surgical safety checklist di Kamar Bedah. Buletin Penelitian Sistem Kesehatan Vol. 17 No. 1 Januari 2013.

UN. (2017). The Sustainable Development Goals Report. United Nations, 1-56.

https://doi.org/10.18356/3405d09f-en

Widiyaningsih, Eni Kusyati, A. H. (n.d.). Hubungan pelaksanaan surgical safety checklist dan kejadian infeksi post operasi mayor. Jurnal IImu Kesehatan Vol.2 No.1, vol 2 no 1.

World Health Organization. (2008). WHO Surgical Safety Checklist Implementation Manual (First Edition). Spring, (September), 1-28. https://doi.org/10.1111/j.17494486.2009.02129.x

World Health Organization. (2017). Patient safety: making health care safer. Patient Safety: Making Health Care Safer., 1-3. https://doi.org/10.1097/NUR.0b013e3181e3 $605 f$ 